\title{
The Nephrotoxic Impact of Oseltamivir in Male Albino Rats after Repeated
} Exposure

\author{
Falah Muosa Kadhim Al-Rekabi \\ College of Vet Medicine, University of Baghdad, Baghdad, Iraq \\ Email: fab20062003@yahoo.com
}

Received 22 February 2014; revised 8 April 2014; accepted 29 April 2014

Copyright (C) 2014 by author and Scientific Research Publishing Inc. This work is licensed under the Creative Commons Attribution International License (CC BY). http://creativecommons.org/licenses/by/4.0/

(c) (i) Open Access

\begin{abstract}
The effects of oseltamivir administration, effectively against influenza viruses $A$ and $B$, on some selected parameters of rat kidney function were investigated to evaluate its possible nephrotoxic effects. Eighteen (18) albino male Wistar rats with body weights ranging from 150 - 190 g were divided into three groups, the first group (T1) was treated orally with $1 \mathrm{mg} / \mathrm{kg} \mathrm{BW}$ as a therapeutic dose of oseltamivir for 7 consecutive days. The second group (T2) was treated with the same dose for six weeks, while the control group was dosed with distilled water. The results revealed a significant increase $(P<0.05)$ in blood urea nitrogen (BUN), serum uric acid and serum creatinine in group $\mathrm{T} 2$, while the $\mathrm{T} 1$ group showed a significant increase $(\mathrm{P}<0.05)$ in serum uric acid only. Kidney histopathological lesions in the T1 rats showed atrophy of the glomerular tufts, dilation of the Bowman's space, deposition of hyaline droplets within the lumen of the proximal and distal convoluted renal tubules, a cloudy swelling of the epithelial cells lining the renal tubules with perivascular lymphocytic cuffing and severe congestion of the interstitial renal blood vessels. The kidneys of the $\mathrm{T} 2$ rats showed necrosis of the epithelial cells lining the renal tubules and cystic dilation with complete dissolution of their epithelial linings. There was vacuolation of the glomerular tuft with proliferation of the parietal layer of the Bowman's capsule, and a serum protein presence in the glomerular space. Mild interstitial fibrosis and thickening of the Bowman's capsule were also observed. Similarly, there was fibrous thickening of the kidney capsule with mild medullary interstitial fibrosis. In conclusion, oseltamivir administered in repeated doses to rats induced some deleterious nephrotoxic effects in a time-dependent manner.
\end{abstract}

\section{Keywords}

Olseltamivir, Nephrotoxic, Albino Rats, Repeated Exposure 


\section{Introduction}

Oseltamivir is an ester prodrug and a potent, selective inhibitor of neuraminidase that results in an inhibition of the release of the influenza virus from host cells and an inhibition of the growth of the influenza virus. Oseltamivir phosphate is used for the treatment of influenza virus infections [1]. It is used in the treatment and prophylaxis of both Influenza virus A and Influenza virus B [2]. Oseltamivir is the most widely used drug but is currently only available as an oral formulation and is eliminated primarily by tubular secretion [3]. The drug is readily absorbed and is converted by hepatic esterase to its active form, oseltamivir carboxylate (OC). The drug is excreted primarily by renal excretion with $60 \%-70 \%$ of an oral dose appearing in the urine as an active metabolite; therefore, dosing must be adjusted in patients with renal impairments [4] [5]. The OC elimination halflife is approximately 6 to $8 \mathrm{~h}$ in adults and up to $13 \mathrm{~h}$ in children and $36 \mathrm{~h}$ in patients with renal failure [6]. The concentrations of a single dose of 14C radiolabeled [2-acetyl-14C] oseltamivir at $10 \mathrm{mg} / \mathrm{kg}$ in rats were widely distributed, with the highest tissue concentrations being observed in the small intestine, liver, stomach, and kidneys $1 \mathrm{~h}$ after dosing. The tissue radioactivity concentrations, with the exception of the large intestine, were lower at $6 \mathrm{~h}$ and were still detectable $24 \mathrm{~h}$ after dosing [7]. The kidney is highly susceptible to toxicants for two reasons: 1) a high volume of blood flows through it and 2) it filters large amounts of toxins, which can concentrate in the kidney tubules resulting in systemic toxicity causing a decreased ability to excrete bodily wastes [8]. This study was conducted to evaluate the possible nephrotoxic effects caused by therapeutic and prophylactic dose regimens of Oseltamivir available pharmaceutically as fluffy ${ }^{\circledR}$ produced by Julphar, Gulf Pharmaceutical Industries, Ras Al-Khaimah, UAE and imported by the medical authorities in Iraq. This study focused on some selected parameters of kidney function supported by a histopathological study.

\section{Material and Methods}

\subsection{The Drugs}

1) Oseltamivir (Flufly) ${ }^{\circledR}$ capsule 75 mg produced by Julphar Gulf Pharmaceutical Indestries, Ras A1-Khaimah, UAE.

2) Ketamine HCl (Ketamin10\%) ${ }^{\circledR}$ obtained from KEPRO-HOLAND and xylazine HCl (XYLAZIN 2\%) obtained from CEVA-GERMANY were used for animal anesthetization for blood collection.

Preparation of oseltamivir solution was achieved by dissolving one capsule $(75 \mathrm{mg})$ in 75 milliliters of distilled water to achieve a concentration of $1 \mathrm{mg} / \mathrm{ml}$

\subsection{Oseltamivir Dosage and Dose}

Each rat was dosed with $0.1 \mathrm{ml} / 100$ gm of body weight of the drug solution, which contained $0.1 \mathrm{mg}$ of oseltamivir at the therapeutic dose of $1 \mathrm{mg} / \mathrm{Kg} \mathrm{BW}$.

\subsection{The Animals}

Male albino Wistar rats with a body weight that ranged from 150 - 190 gm were procured from the animal house of the College of Veterinary Medicine, University of Baghdad and were maintained in an air-conditioned room $\left(25^{\circ} \mathrm{C} \pm 1^{\circ} \mathrm{C}\right)$ with a 12 hours light: 12 hours dark cycle. Standard pellet diet and water were provided ad libitum [9].

\subsection{Experimental Design}

This work was performed with the approval of the College of Veterinary Medicine/Baghdad University in accordance with international ethical standards of research for work with laboratory animals.

\subsection{Clinical Study}

Eighteen male rats were divided equally into three groups (T1, T2 and control) and were subjected to a blood biochemical analysis. The two treatment groups T1 and T2 were dosed orally by gastric gavage at a dose of 1 $\mathrm{mg} / \mathrm{Kg}$ BW for one and six weeks, respectively, while the control group was dosed with distilled water. Blood was collected from the animals in all the groups by heart puncture after anesthesia with $0.1 \mathrm{ml} / 100 \mathrm{gm}$ BW of ketamine $10 \%$ and $0.1 \mathrm{ml} / 100 \mathrm{gm} \mathrm{BW}$ of xylazine $2 \%$ post treatment. The serum was obtained from all the 
blood samples by centrifugation at $5000 \mathrm{r}$ per minute for five minutes.

\subsection{Histopathology}

The animals in all the groups were sacrificed at the end of the dosing period. The kidneys were obtained and preserved in $10 \%$ formalin, then sent to the MEDICINAL CITY HOSPITAL laboratory for histopathology processing as previously described [10].

\subsection{Blood Biochemical Analysis}

Serum uric acid was assessed using a commercially available kit (Bio System-SPAIN). The principle of this method depends on the coupled quinonemine reaction results that are measured by spectrophotometry [11].

Blood urea nitrogen (BUN) was assessed using a commercially available kit (RANDOX-UK). The modified urease-Bertheholt method was used, and is based on the formation of a green complex of 2 - 2 dicarboxylindophenol [12].

Serum creatinine was assessed using a commercially available kit (BioSystem-SPAIN). The method depends on the reaction of serum creatinine with picrate in an alkaline medium, forming a colored complex, which is then measured by spectrophotometry [13].

Statistical analysis was performed using SPSS version 13.00. A one-way ANOVA was used for the assessment of the differences between the groups. A P-value $<0.05$ was considered statistically significant. LSD multiple range tests were performed for comparisons between the means [14].

\section{Results}

\subsection{Uric Acid}

There were significant increases $(\mathrm{P}<0.05)$ in the serum uric acid of the rats that had been given the therapeutic dose of $1 \mathrm{mg} / \mathrm{kg}$ BW for one week $(4.56 \pm 0.20 \mathrm{mg} / \mathrm{dL})$ and six weeks $(5.43 \pm 0.34 \mathrm{mg} / \mathrm{dL})$ in comparison with the serum uric acid of rats in the control group, which was $(2.16 \pm 0.09) \mathrm{mg} / \mathrm{dL}$, as shown in Table 1.

\subsection{Blood Urea Nitrogen (BUN)}

There was a significant decrease $(\mathrm{P}<0.05)$ in the blood urea nitrogen (BUN) of the rats given a therapeutic dose of oseltamivir at $1 \mathrm{mg} / \mathrm{kg}$ BW for six weeks recorded at $25.33 \pm 2.24 \mathrm{mg} / \mathrm{dL}$ in comparison with $59.33 \pm 2.70$ $\mathrm{mg} / \mathrm{dL}$ for the same therapeutic dose of oseltamivir given for one week; there was also a significant difference between $\mathrm{T} 1$ and the control group at $57.34 \pm 3.73 \mathrm{mg} / \mathrm{dL}$, see Table 2 .

\subsection{Serum Creatinine}

There was a significant increase $(\mathrm{P}<0.05)$ in serum creatinine in the rats dosed with oseltamivir at $1 \mathrm{mg} / \mathrm{kg} \mathrm{BW}$ for six weeks $(1.31 \pm 0.10 \mathrm{mg} / \mathrm{dL})$ in comparison with the rats given the same therapeutic dose for one week $(0.55 \pm 0.04 \mathrm{mg} / \mathrm{dL})$ and the rats in the control group $(0.60 \pm 0.10 \mathrm{mg} / \mathrm{dL})$. No significant differences were observed between $\mathrm{T} 1$ and the control group, see Table 3 .

\subsection{Histopathology}

The kidneys of the rats given the therapeutic dose of $1 \mathrm{~m} / \mathrm{kg}$ BW of oseltamivir for one week showed atrophy of the glomerular tufts with dilation of the Bowman's space and deposition of hyaline droplets within the lumen of the proximal and distal convoluted renal tubules (Figure 1). There was also a cloudy swelling of the epithelial cells lining the renal tubules with perivascular lymphocytic cuffing (Figure 2). In addition, there was severe congestion of the interstitial renal blood vessels; many of them were dilated and contained large numbers of neutrophils.

The kidneys of rats given the therapeutic dose of $1 \mathrm{~m} / \mathrm{kg}$ BW of oseltamivir for six weeks showed massive necrosis of the epithelial cells lining the renal tubules. Many of the renal tubules showed cystic dilation with a complete dissolution of their epithelial linings (Figure 3). Additionally, there was vacuolation of the glomerular tufts with proliferation of the parietal layer of the Bowman's capsule and a serum protein presence in the 
Table 1. Serum uric acid in $\mathrm{mg} / \mathrm{dL}$ in rats dosed orally with the therapeutic dose of $1 \mathrm{mg} / \mathrm{kg}$ BW of oseltamivir for different periods.

\begin{tabular}{cllll}
\hline Group & \multicolumn{4}{c}{ Serum uric acid mg/dL } \\
\\
T1 & 4.56 & & SE & \\
T2 & 5.43 & & 0.20 & A \\
C & 2.16 & & 0.34 & B \\
\hline
\end{tabular}

$\mathrm{T} 1$ = therapeutic dose of $1 \mathrm{mg} / \mathrm{kg} \mathrm{BW}$ of oseltamivir for one week. T2 = therapeutic dose of $1 \mathrm{mg} / \mathrm{kg} \mathrm{BW}$ of oseltamivir for six weeks. $\mathrm{C}=$ control dosed with distilled water. The capital letters denote significant differences between the groups at the $\mathrm{P}<0.05$ level.

Table 2. Blood urea nitrogen (BUN) in $\mathrm{mg} / \mathrm{dL}$ of the rats given a therapeutic dose of oseltamivir orally at $1 \mathrm{mg} / \mathrm{kg}$ BW for different periods.

\begin{tabular}{ccccc}
\hline \multirow{2}{*}{ Group } & \multicolumn{4}{c}{ Serum creatinine mg/dL } \\
& M & \pm & SE & \\
T1 & 59.33 & & 2.70 & A \\
T2 & 25.33 & & 2.24 & B \\
C & 57.34 & & 3.73 & A \\
\hline
\end{tabular}

$\mathrm{T} 1$ = therapeutic dose of $1 \mathrm{mg} / \mathrm{kg} \mathrm{BW}$ of oseltamivir for one week. T2 = therapeutic dose of $1 \mathrm{mg} / \mathrm{kg} \mathrm{BW}$ of oseltamivir for six weeks. $\mathrm{C}=$ control dosed with distilled water. The capital letters denote significant differences between the groups at the $\mathrm{P}<0.05$ level.

Table 3. Serum creatinine in $\mathrm{mg} / \mathrm{dL}$ of the rats given the therapeutic dose of $1 \mathrm{mg} / \mathrm{kg} \mathrm{BW}$ of oseltamivir orally for different periods.

\begin{tabular}{ccrrr}
\hline \multirow{2}{*}{ Group } & \multicolumn{4}{c}{ Serum creatinine $\mathrm{mg} / \mathrm{dL}$} \\
\\
$\mathrm{T} 1$ & 0.55 & & $\mathrm{SE}$ & \\
$\mathrm{T} 2$ & 1.31 & & 0.04 & $\mathrm{~A}$ \\
$\mathrm{C}$ & 0.60 & & 0.10 & $\mathrm{~B}$ \\
& & 0.10 & $\mathrm{~A}$ \\
\hline
\end{tabular}

$\mathrm{T} 1$ = therapeutic dose of $1 \mathrm{mg} / \mathrm{kg} \mathrm{BW}$ of oseltamivir for one week. T2 = therapeutic dose of $1 \mathrm{mg} / \mathrm{kg} \mathrm{BW}$ of oseltamivir for six weeks. $\mathrm{C}=$ control dosed with distilled water. The capital letters denote significant differences between the groups at the $\mathrm{P}<0.05$ level.

glomerular space. Mild interstitial fibrosis leading to thickening of the Bowman's capsule was also observed (Figure 4). Similarly, there was a fibrous thickening of the kidney capsule that was infiltrated with chronic inflammatory cells. There was also mild medullary interstitial fibrosis (Figure 5).

\section{Discussion}

Biochemical markers play an important role in accurate diagnoses, assessing risks and adopting therapies that improve clinical outcomes. As markers of renal function, serum creatinine, blood urea nitrogen (BUN) and uric acid are routinely used for analysis [15]. Elevated uric acid is one of the most important risk factors for cardiovascular disease; it plays a significant role in the development of renal disease and metabolic syndrome, and high serum urate levels are usually associated with defects in uric acid transport [16]. An elevated uric acid level often precedes kidney disease [17]. The repeated dosing of oseltamivir at $1 \mathrm{mg} / \mathrm{kg}$ BW throughout the period of the present study resulted in distinct pathological changes in the kidneys of the rats in both treated groups and was shown in Figures 1-5.

Urea is a major nitrogenous end product of the protein and amino acid catabolism produced by the liver and is distributed throughout the intracellular and extracellular fluid [15]. Low blood urea levels are seen in trauma and surgery and are associated with the use of some drugs, anabolic steroid use and malnutrition [18]. The significant reduction in the blood urea nitrogen concentration throughout the experimental period may be attributed to impairment of the urea cycle (in the liver) leading to the reduced production of metabolic products [19]. This is an indication of an abnormality in the physiological excretion of urea caused by a non-renal factor [20]. We considered that the reduction in the blood urea nitrogen level was due to the hepatotoxic effects of oseltamivir 


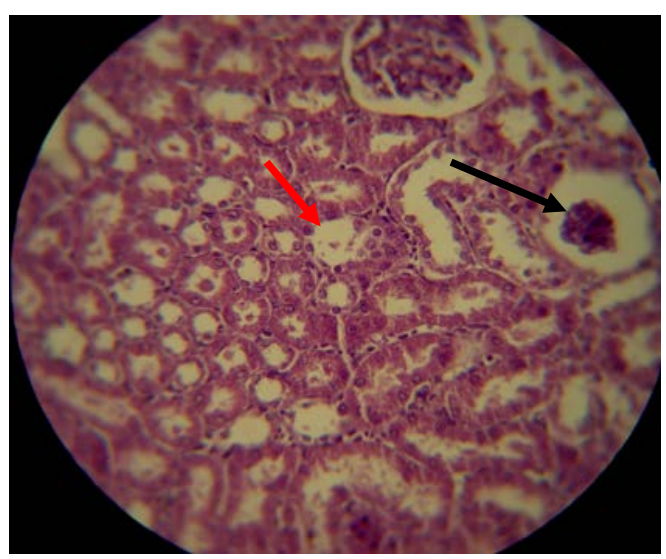

Figure 1. The kidney of a male rat dosed with 1 $\mathrm{mg} / \mathrm{kg}$ BW of oseltamivir for one week and showing atrophy of the glomerular tufts with the dilation of the Bowman's space (black arrow) and with the deposition of hyaline droplets in the lumina of the proximal and distal convoluted tubules (red arrow) (H\&E 100×).

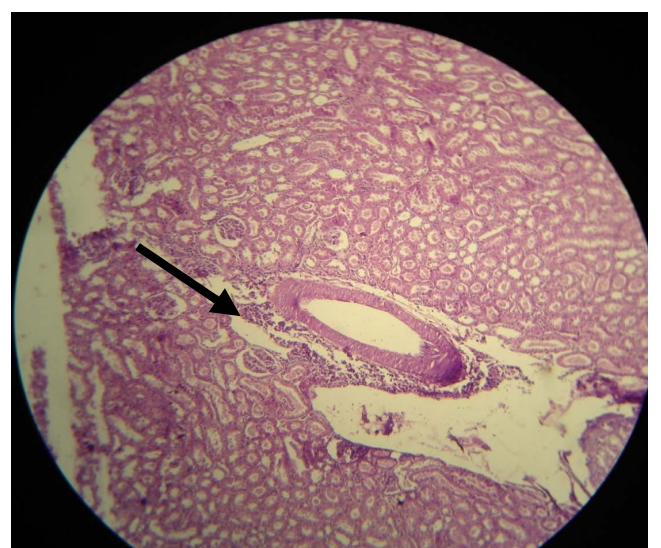

Figure 2. The kidney of a male rat dosed with 1 $\mathrm{mg} / \mathrm{kg}$ BW of oseltamivir for one week and showing perivascular lymphocytic cuffing (black arrow) (H\&E 100×).

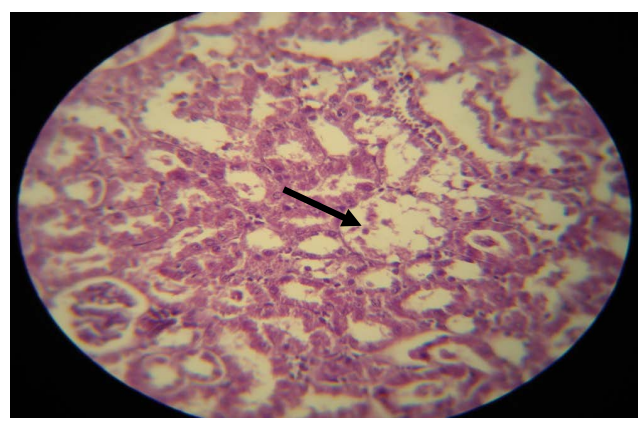

Figure 3 . The kidney of a male rat dosed with 1 $\mathrm{mg} / \mathrm{kg}$ BW of oseltamivir for six weeks showing cystic dilation of the cortical renal tubules with complete dissolution of their epithelial lining (black arrow) (H\&E 100×). 


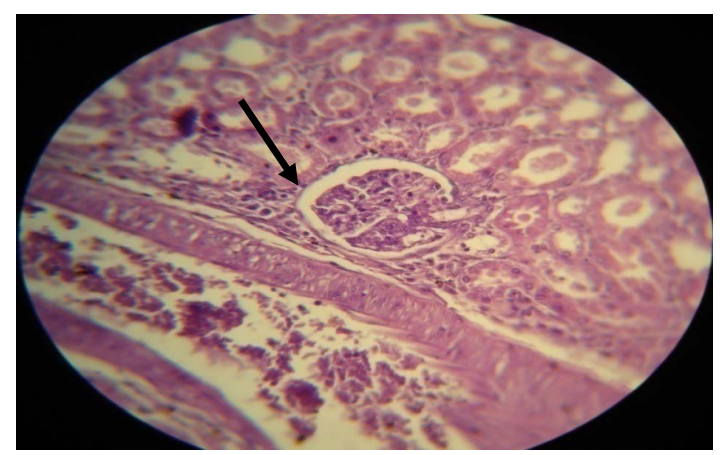

Figure 4. The kidney of a male rat dosed with $1 \mathrm{mg} / \mathrm{kg}$ BW of oseltamivir for six weeks showing interstitial fibrosis leading to thickening of the Bowmans capsule (black arrow) (H\&E 100×).

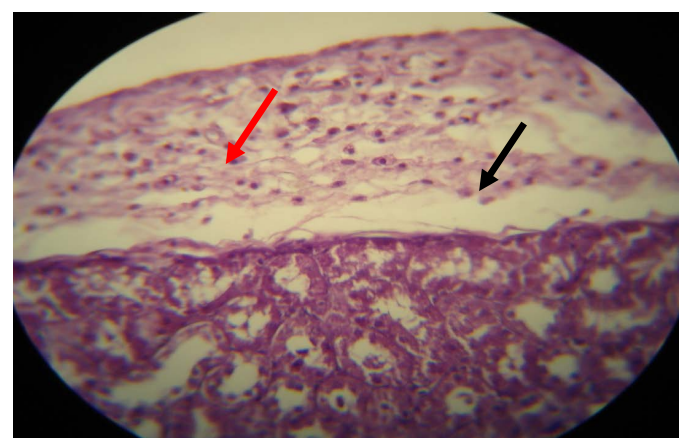

Figure 5. The kidney of a male rat dosed with 1 $\mathrm{mg} / \mathrm{kg}$ BW of oseltamivir for six weeks showing fibrous thickening of the capsule (black arrow) with the infiltration of chronic inflammatory cells (red arrow) (H\&E 100×).

dosed at $1 \mathrm{mg} / \mathrm{kg}$ BW for six weeks. We reached this conclusion by histopathological analysis and other liver function tests including alaninaminotrasferase (ALT), aspartate aminotrasferase (AST), alkaline phosphatase (AP), total bilirubin, conjugated and non-conjugated bilirubin and total serum protein [21]. The liver is the site of the urea cycle. However, the effects of the drug were not obvious at one week of dosing because the BUN level in the T1 group was similar to that in the control group.

Creatinine is commonly used as a measure of kidney function, and the calculation of the glomerular filtration rate may be derived from the serum creatinine level [22]. A diagnosis of renal failure is usually suspected when the serum creatinine is greater than the upper limit of the normal interval; in chronic renal failure and uremia, an eventual reduction in the excretion of creatinine by both glomeruli and tubules occurs [23]. These events are confirmed by histopathological findings in the kidneys of the rats treated with $1 \mathrm{mg} / \mathrm{kg} \mathrm{BW}$ of oseltamivir for six weeks, which included cystic dilation of the cortical renal tubules with complete dissolution of their epithelial lining (Figure 3) and thickening of the Bowman's capsule (Figure 4).

Oseltamivir induced kidney injury in rats treated with $0.1 \mathrm{mg} / \mathrm{kg} \mathrm{BW}$ for one and six weeks through the increased level of uric acid (Table 1). In other studies in rats, experimental hyperuremia (induced by oxonic acid) has also been associated with the development of mild renal disease, characterized by mild proteinuria, renal arteriolar changes, glomerular hypertrophy, tubulointerstitial fibrosis, and eventually glomerulosclerosis [24]. Interestingly, when hyperuremia was induced in rats with preexisting renal disease (i.e., in which one entire kidney and two thirds of the other kidney had been removed), their renal lesions were dramatically worse than in similar rats without hyperuremia [25]. This suggests that the hyperuremia may not only cause renal disease but also exacerbate preexisting renal disease. The mechanism by which uric acid might cause renal disease was revealed by micropuncture studies that demonstrated that elevated uric acid $(3.1 \pm 0.2 \mathrm{mg} / \mathrm{dL})$ caused glomerular 
hypertension and cortical vasoconstriction [26]. These changes would be expected to induce glomerular damage and tubular ischemia. In addition, uric acid stimulated inflammatory mediators in vascularcells, including Creactive protein and monocyte chemoattractant protein-1p [27] [28] and vasoconstrictive factors such as thromboxane [25]. After oral administration, oseltamivir is rapidly hydrolyzed to its active metabolite oseltamivir carboxylate (OC), which is then excreted by glomerular filtration and renal tubular secretion without further metabolism [29]. When rats are unable to hydrolyze the oseltamivir phosphate sufficiently to its metabolite, an excessive amount of phosphate will accumulate. This would negatively affect the dietary calcium/phosphate ratio in species known to be sensitive to this type of change and would consequently lead to mineralization of the kidney [30].

The results of this study suggest that the rats that had been exposed repeatedly to $1 \mathrm{mg} / \mathrm{kg}$ BW of oseltamivir experienced several deleterious effects on kidney function depending on the period of dosing, as shown by serum biochemical markers. Oseltamivir, when given at low therapeutic doses for prophylaxis (six weeks) caused renal damage; therefore, kidney and liver function tests must be performed during OM prophylaxis therapy.

\section{References}

[1] Shigeru, O., Eiichi, N.M.K., Yukiya, S. and Daisuke, K. (2009) Penetration of Oseltamivir and Its Active Metabolite into the Brain after Lipopolysaccharide-Induced Inflammation in Mice. Journal of Pharmacy and Pharmacology, 61, 1397-1400. http://dx.doi.org/10.1211/jpp.61.10.0018

[2] Bardsley, E.A. and Noble, S. (1999) Oseltamivir. Drugs, 58, 851-860. http://dx.doi.org/10.2165/00003495-199958050-00007

[3] Chairat, K., Tarning, J., White, N.J. and Lindegardh, N. (2013) Pharmacokinetic Properties of Anti-Influenza Neuraminidase Inhibitors. Journal of Pharmacy and Pharmacology, 53, 119-139.

[4] Saw, J.T. and Hong, L.W. (2007) Oseltamivir in the Treatment of Avian Flu (H5N1). JASA, 2, 46-49.

[5] He, G. (1999) Clinical Pharmacokinetics of the Prodrug Oseltamivir and Its Active Metabolite Ro 64-0802. Clinical Pharmacokinetics, 37, 471-484. http://dx.doi.org/10.2165/00003088-199937060-00003

[6] Robson, R.A., Buttimore, K., Lynn, M.B. and Ward. P. (2006) The Pharmacokinetics and Tolerability of Oseltamivir Suspension in Patients on Hemodialysis and Continuous Ambulatory Peritoneal Dialysis. Nephrology, Dialysis, Transplantation, 21, 2556-2562. http://dx.doi.org/10.1093/ndt/gfl267

[7] Sweeny, D.J., Lynch, G, Bidgood, A.M., Lew, W., Wang, K.Y. and Cundy, K.C. (2000) Metabolism of the Rat Influenza Neuraminidase Inhibitor Prodrug Oseltamivir in the Rat. Drug Metabolism and Disposition, 7, 737-774.

[8] Emily, M. (2007) Toxicity. In: Cutler, J., Ed., Encyclopedia of Earth, Cleveland, Washington DC.

[9] Hafez, E.S.E. (1970) Reproduction and Breeding Techniques for Laboratory Animals. Lea and Febiger, Philadelphia.

[10] Luna, L.G. (1968) Manual of Histology Staining Methods of the Armed Forces Institute of Pathology. 3rd Edition, McGraw Hill Book Co., New York.

[11] Fossati, P., Prencipe, L. and Berti, G. (1980) Use of 3,5-Dichloro-2-Hydroxybenzenesulfonic Acid/14-Aminophenazone Chromogenic System in Direct Enzymic Assay of Uric Acid in Serum and Urine. Clinical Chemistry, 26, 227231.

[12] Fawcett, J.K. and Scott, J.E. (1960) A Rapid and Precise Method for the Determination of Urea. Journal of Clinical Pathology, 13, 156-159. http://dx.doi.org/10.1136/jcp.13.2.156

[13] Bartels, H. and Bohmer, M. (1971) Eine Mikromethode zur Kreatininbestimmung. Clinical Chimica Acta, 32, 81-85.

[14] Joda, M. (2008) The Progressive Statistical Analyses by Using SPSS. 1st Edition, Churchill Livingstone, Edinburgh.

[15] Gowda, S., Desai, P.B., Kulkarni, S.S., Hull, V.V., Math, A.A.K. and Vernekar, S.N. (2010) Marker of Renal Function Tests. North American Journal of Medical Sciences, 4, 170-173.

[16] Heinig, M. and Johnson, R.J. (2005) Role of Uric Acid in Hypertension, Renal Diseases and Metabolic Syndrome. Cleveland Clinic Journal of Medicine, 12, 1059-1064. http://dx.doi.org/10.3949/ccjm.73.12.1059

[17] Iseki, K., Oshiro, S., Tozawa, M., Iseki, C., Ikemiya, X. and Takishita, S. (2001) Significance of Hyperuricemia on the Early Detection of Renal Failure in a Cohort of Screened Subjects. Hypertension Research, 24, 691-697. http://dx.doi.org/10.1291/hypres.24.691

[18] Pagana, K.D. (2002) Mosby’s Manual of Diagnosis and Laboratory Tests. Mosby, St. Louis.

[19] Rodwell, V.W. (1996) Catabolism of Proteins and Amino Acid Nitrogen. In: Murray, R.K., Granner, D.K., Mayes, P.A. and Rodwell, V.W., Eds., Harpers Biochemistry, 24th Edition, Prentice-Hall International, Upper Saddle River, 305308. 
[20] Segasolhy, M., Swoninalhua, M. and Kong, N.C. (1994) Acute Renal Failure in Folciparum Malaria. Medical Journal of Malaysia, 49, 412-415.

[21] Al-Rikabi, F.M.K. (2012) Evaluation of Selected Parameters of Rat Liver Injury Following Repeated Administration of Oseltamivir for Different Periods. Iraqi Journal of Veterinary Medicine, 1, 137-144.

[22] Miller, W., Myers, G., Ashwood, E., Killeen, A.A., Wang, E., Thienpont, L.M., et al. (2005) Creatinine Measurement State of the Art in Accuracy and Interlaboratory Harmonization. Archives of Pathology \& Laboratory Medicine, 3, 297-304.

[23] Edmund, L. and David, J. (2006) Kidney function tests. In: Burtis, C., Ashwood, E. and Burns, D., Eds., Tietz Textbook of Clinical Chemistry and Molecular Diagnostics, 24th Edition, Elsevier, New Delhi, 797-808.

[24] Nakagawa, T., Mazzali, M., Kang, D.H., Kanellis, J., Watanabe, S., Sanchez-Lozada, L.G., et al. (2003) Hyperuricemia Causes Glomerular Hypertrophy in the Rat. American Journal of Nephrology, 23, 2-7. http://dx.doi.org/10.1159/000066303

[25] Kang, D.H., Nakagawa, T., Feng, L., Watanabe, S, Han L, Mazzali M., et al. (2002) A Role for Uric Acid in the Progression of Renal Disease. Journal of the American Society of Nephrology, 13, 2888-2897. http://dx.doi.org/10.1097/01.ASN.0000034910.58454.FD

[26] Sanchez-Lozada, L.G., Tapia, E., Avila-Casado, C., Soto, V., Franco, M., Santamaría, J., et al. (2002) Mild Hyperuricemia Induces Glomerular Hypertension in Normal Rats. American Journal of Physiology. Renal Physiology, 283, F1105-F1110.

[27] Kang, D.H., Park, S.K., Lee, I.K. and Johnson, R.J. (2005) Uric Acid-Induced C-Reactive Protein Expression: Implication on Cell Proliferation and Nitric Oxide Production of Human Vascular Cells. Journal of the American Society of Nephrology, 16, 3553-3562. http://dx.doi.org/10.1681/ASN.2005050572

[28] Kanellis, J., Watanabe, S., Li, J.H., Kang, D.H., Li, P., Nakagawa, T., et al. (2003) Uric Acid Stimulates Monocyte Chemoattractant Protein-1 Production in Vascular Smooth Muscle Cells Via Mitogen-Activated Protein Kinase and Cyclooxygenase-2. Hypertension, 41, 1287-1293. http://dx.doi.org/10.1161/01.HYP.0000072820.07472.3B

[29] Abe, M., Smith, J., Urae, A., Barrett, J., Kinoshita, H. and Rayner, C.R. (2006) Pharmacokinetics of Oseltamivir in Young and Very Elderly Subjects. Annals of Pharmacotherapy, 40, 1724-1730. http://dx.doi.org/10.1345/aph.1H174

[30] Farrely, J. (2001) Pharmacologists' Review. Application Number 21-246, Center for Drug Evaluation and Research, $1-18$. 